\title{
sciendo

\section{On the Imaginary Accuracy of the LCA on the Basis of the Houseboat in Hamburg (Holistic Approach)}

\author{
Maria GRAJCAR ${ }^{1 *}$, Kristina RUMIANTCEVA ${ }^{2}$, Ingo WEIDLICH ${ }^{3}$ \\ ${ }^{1-3}$ HafenCity University Hamburg, Überseeallee 16, Hamburg, 20457, Germany
}

\begin{abstract}
To our knowledge, for the first time in the history of the life cycle assessment, the LCA analysis of the houseboats used for residential purposes has been conducted while testing a new software program eLCA in its Beta version. In cooperation with the Coop Waterhouse GmbH and with the Architektenbüro PlanWerk, the houseboat Swan, due to its extraordinary solutions for energy supply, has been chosen for the first attempt at analysing uncertainty in its LCA with the focus on the energy supply components as well as on the energy input. Results discuss energy usage, being responsible for the half of the total $\mathrm{CO}_{2}$ e-emissions, and its uncertainty with regards to the next 50 years of the houseboat's lifetime.
\end{abstract}

Keywords - eLCA software program; energy use; houseboat; LCA (Life Cycle Assessment); uncertainty analysis

\section{INTRODUCTION}

Most of us incorporate outcomes of research projects into our teaching classes whenever it seems plausible. This time, the conventional order took place in reverse - and what at first seemed to be just a new concept of teaching the "Life Cycle Assessment" to Masters Students became a research question: how accurate are the results of the LCA analysis of houseboats in Hamburg, which have already been built?

The LCA and modern houseboats built for residential purposes share the notion of novelty - both with their roots in the 1960s and 1970s. In a massive growing city such as Hamburg, houseboats contribute to the visual experience of the city and to solving the accommodation problem for some families. The chosen houseboat named Swan, is a non-motorised floating boat on the Norderkai shore in Hammerbrook, Hamburg (Fig. 1). This houseboat has been selected due to its extraordinary mix of installations based on renewable energy (Table 1) including a pellet boiler installed in the living room with remarkable aesthetic value (Fig. 2), PV-panels, water storage, and solar panels. Pellets for the Swan have been purchased from the Hamburg region ${ }^{\dagger}$.

\footnotetext{
* Corresponding author.

E-mail address: maria.grajcar@hcu-hamburg.de

$\dagger$ Surprisingly, Germany is a net wood pellet exporter [1]. 
Table 1. Houseboat Swan Technical Specification (Source: PlanWerk Architektur)

\begin{tabular}{ll}
\hline Characteristics & Houseboat Swan, year of construction: 2014 \\
\hline Gross floor area & $120 \mathrm{~m}^{2}$ \\
Internal floor area & $96 \mathrm{~m}^{2}$ \\
$\begin{array}{l}\text { Heating, ventilation, air } \\
\text { conditioning }\end{array}$ & $\begin{array}{l}\text { Pellet boiler, PV-panels, water storage, solar panels, } \\
\text { ventilation system with heat recovery }\end{array}$ \\
\hline
\end{tabular}

Besides discussing the methods, the chapter Methods and Procedures contains a short description of the software program eLCA (Section 2.1) and the Calculation of the Energy Input (Section 2.2). Chapter 3 discusses various kinds of uncertainty with the relevant examples from current literature on the topic. Outcomes of the LCA for Global warming potential are depicted in the Results section as well as first estimations for the impact of changing energy supply technologies on these results.

$$
\text { Object Tool/Approach Results }
$$

\begin{tabular}{|c|c|c|c|}
\hline 1st line & Houseboat & eLCA & $\begin{array}{c}\text { Potential impact on } \\
\text { GWP and PE } \\
\text { Input for }\end{array}$ \\
\hline 2nd line & Uncertainty & Holistic & $\begin{array}{l}\text { Discussion part on } \\
\text { uncertainty of results }\end{array}$ \\
\hline
\end{tabular}

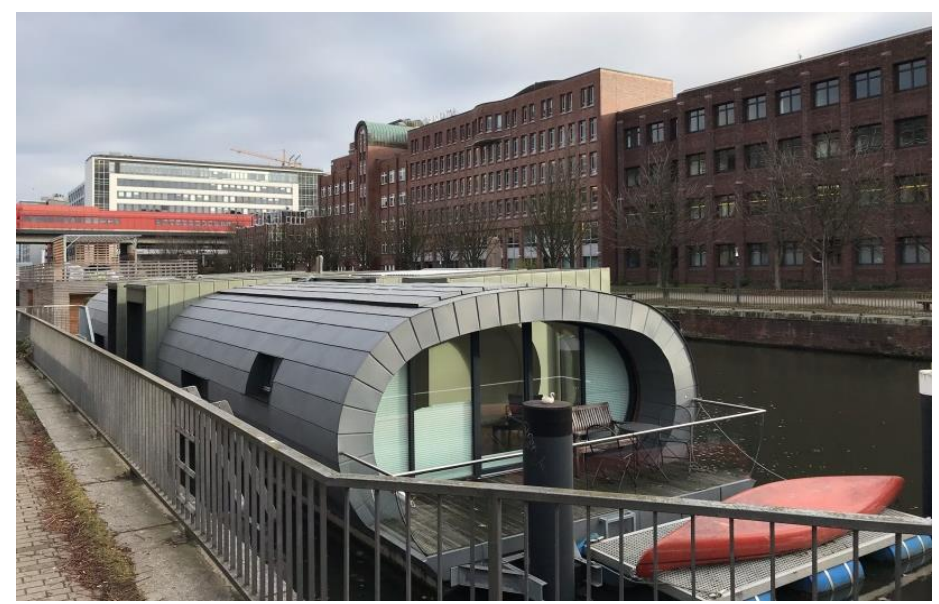

Fig. 1. Houseboat Swan. Author: Cesar Pascoli. 


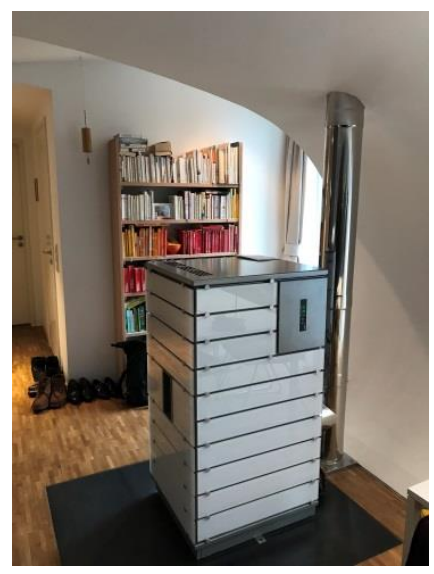

Fig. 2. Wood pellet boiler. Author: Cesar Pascoli.

\section{Methods And Procedures}

The life cycle assessment of the houseboat being analysed has been conducted with the eLCA tool [2].

The eLCA is an online life cycle assessment tool (www.bauteileditor.de), in which the entire life cycle of a building can be reconstructed with the ÖKOBAUDAT database. It was created for a German LCA market and since the houseboat Swan is located in Hamburg, compliance with German norms and standards was compulsory. The basis for the calculation and assessment has been derived from the calculation rules in the BNB system (The Assessment System for Sustainable Building, www.bnb-nachhaltigesbauen.de). Primarily, the BNB System has been developed for a planning-based evaluation system for office and administrative buildings in Germany. Its structure already represents system thinking similar to Life Cycle Sustainability Assessment thanks to addressing not only ecological quality (LCA) but also economic and sociocultural quality for example.

Its roots in the public sector explain one peculiarity of the software tool; the requirement to include the net floor area (Nettogrundfläche, NGF) instead of the living area (Wohnfläche). The net floor area includes the usable floor area, the floor area of technical rooms and the area for the circulation area.

Still, the eLCA can be used for any residential building as a) the difference would be not more than $3 \%$; b) the user can choose the living area; the software program automatically calculates the results for any area in square meters used.

The ÖKOBAUDAT database is compliant with the Assessment System for Sustainable Building (BNB) and with DIN EN 15804 - Sustainability of construction works Environmental product declarations - Core rules for the product category of construction products. Moreover, the data base is based on the background database GaBi. Although additional datasets based on the Swiss Ecoinvent background data are published on the ÖKOBAUDAT platform, they cannot be used in the eLCA tool [3].

During the research process, two different kinds of methodologies were used, described in Step 1 and Step 2 respectively:

- Step 1. The methodology of the LCA of houseboats according to the international standards ISO 14040 and ISO 14044; including setting the boundary conditions (Section 2.3), compiling an inventory analysis of Swan (Table 2) and running the 
eLCA software program;

- Step 2. Parameter, scenario and model uncertainty analysis $*$ with the focus on energy producing components and electricity delivery. The LCA is a model-based assessment tool itself and as such is always associated with large uncertainties $\$$;

- Step 3. Uncertainty squared - estimations of the future development of energy supply technologies on the total results for houseboat Swan.

In the eLCA, the construction phases A4 and A5 are not considered (Fig. 3), which seems to be plausible. However, the software tool does not count with the maintenance B2, replacement of the houseboat B4 and refurbishment B5, only the energy usage B6 from the use stage could have been considered. As, in standard buildings, it is still mostly the heating and cooling (use phase) that influences the potential of environmental burden assessed by impact indicators, this justifies our sole focus on energy use.

In the assessment of nearly zero energy buildings, other phases of the LCA will become prominent and thus unavoidable for assessing the impacts. In the End of Life Cycle section, waste processing C3 and disposal C4 have been considered. In our case we also have not considered D - benefits and loads beyond the system boundary (Fig. 3) although the software program offers this function.

The energy mix of Germany (base year 2015) is used for calculations and theoretically remains the same through the lifetime of the houseboat. This implies rather conservative results of the eLCA calculations. In other words, the function of continual improvement of technological factors has not been implemented in the eLCA and this is also the reason for Step 2.

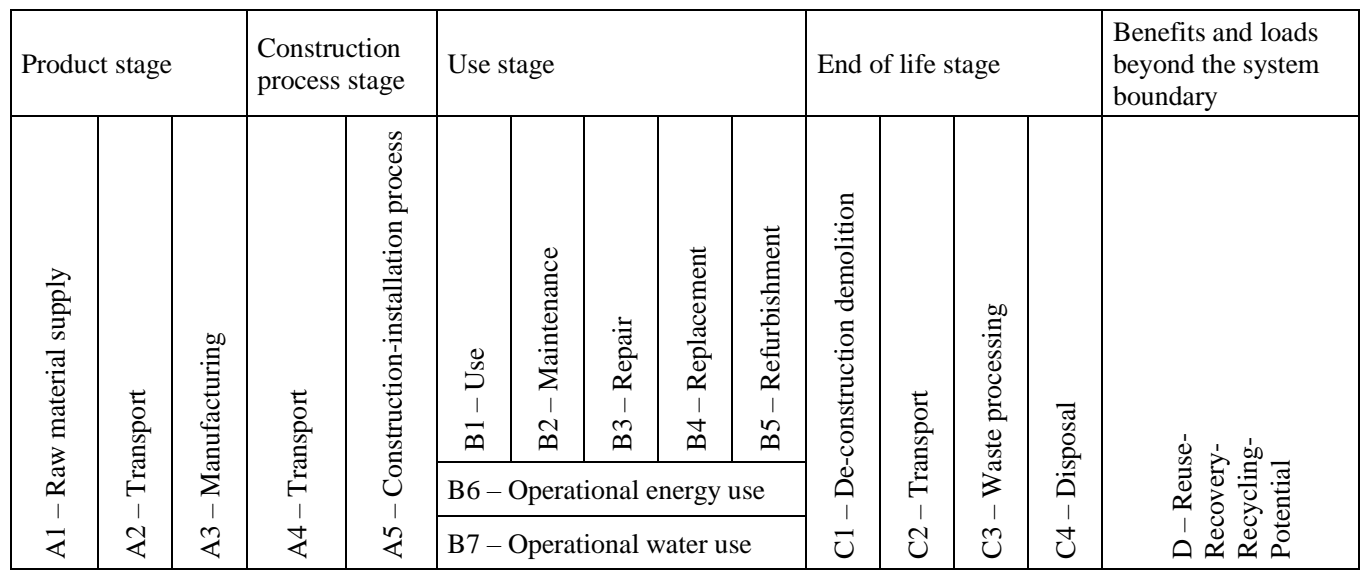

Fig. 3. Life Cycle Modules in accordance with EN 15804. Source: EN 15804.

To sum up this part, the eLCA, like many other software programs used for conducting the life cycle analysis of the chosen functional unit of the product, assists in answering the questions that follow:

\footnotetext{
$\$$ The sensitivity and uncertainty analysis do not overlap. The sensitivity analysis estimates the effects on the outcome of a study of the chosen methods and assumptions. A model is sensitive toward a parameter if a small change in this parameter will result in a large change in the model result [4];

$\S$ Realising this has led to the deep disappointment of some students during their Masters course on the LCA in the Winter term 2018/2019.
} 
- Are components made of wood really the most ecological and sustainable materials used in the construction?

- Why is there a zero value in the category of primary non-renewable energy in materials e.g. photovoltaic (PV) panels in the eLCA tool? If this value is zero, which category is influenced by including PV panels in the inventory list of the houseboat Swan?

- How would the hypothetical replacement of the pellet boiler for a gas boiler or for the connection to the district heating network in Hamburg change the overall results of the LCA?

As an example, question b) was chosen to be answered. The categorization of non-renewable primary energy into 1) Non-renewable energy used as energy input in the production process and 2) non-renewable energy used as a material in the production process, make further suggestions for improvement (i.e. decreasing the potential) of production process comprehensible. In case of photovoltaic panels, material ranking, one of the evaluation sections in the eLCA, displays panels in second place while choosing the general category of non-renewable primary energy (39.41 MJ for one square meter of the PV panels). Going one step further, the evaluation reveals $0 \mathrm{MJ}$ of non-renewable primary energy used as a material consumed while producing PV panels. This shall not be interpreted as a mistake in a software program but mirrors the fact that no oil or gas products have been directly used for the production of PV panels. Relevant chemical elements, rare materials included, are to be found in the impact category Abiotic Depletion Potential (ADP). Abiotic resources are natural resources (including energy resources), such as iron ore and crude oil, which are regarded as non-living [5]. In this category, panels are found in first place in the ranking, followed by components made out of steel and solar collectors.

Throughout the work done on the LCA of houseboats, a few more questions emerged that very few software programs could answer: How to solve customers' preferences for design or quality of architecture over sustainability issues (for instance, the comparison of larch wood in the houseboat Swan to plywood or sawn hardwood). This issue of preference can be scaled down to the building component, for example, shall carbon dioxide or sulphur dioxide reduction technologies be installed in the glass manufacture process, even if they negatively affect the life time of the furnace or the quality of the glass?

These questions have been left unanswered with a single remark. The theory of bounded rationality and common sense claim all stakeholders make reasonable decisions based on the information they have. In all models, representing economy, energy sector or the life cycle, rationality is an embedded factor to be counted on. Still, rationality and aesthetics do not necessarily overlap; the second preference has been overlooked in every model.

The following subsections 2.1 and 2.2 describe the work with the eLCA from the user's point of view and may be beneficial for a) a reader already familiar with other software tools for conducting the LCA for buildings, b) anybody interested in conducting his/her future LCA with the free eLCA software tool. To facilitate the first contact with the eLCA, the translation of relevant expressions into German has been included in brackets.

\subsection{Short Description of the eLCA}

The eLCA software program allows a user to create a model of the building using three main groups of elements - Building (Bauwerk), Building Services (Haustechnik) and Grounds (Außenanlagen).

Group Building contains constructive elements of the building like exterior and interior walls, roofs, ceiling and the foundation (Table 2). Each element is divided into subcategories providing an opportunity to work with specific items it contains. For instance, under the item 
"walls", load-bearing and non-load-bearing constructions can be specified, as well as columns, doors, and windows. Other elements are divided into subcategories by the same principle. Group Building Services includes heating supply systems, telecommunications, and information processing systems; under "Use-specific systems" one finds kitchen equipment, disposal facilities, and others. Outdoor facilities like playgrounds, parking lots and gardens can be modelled in the third group of elements - Grounds.

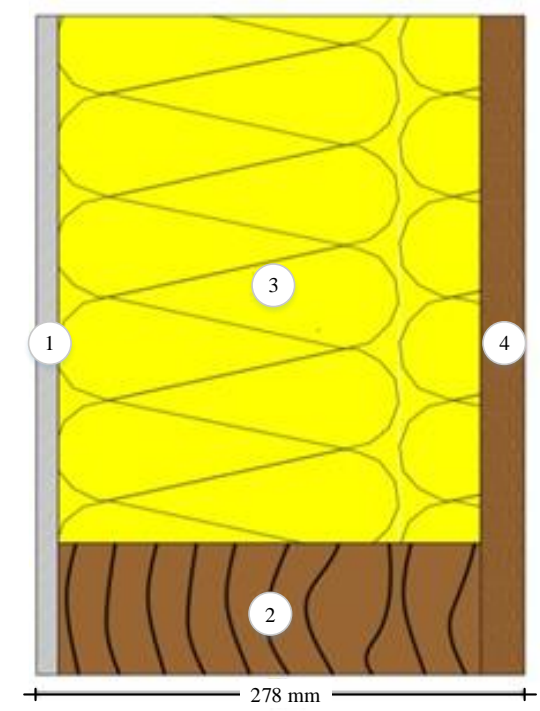

1. Gypsum plasterboard in accordance with DIN EN 520 and DIN 18180, $12.50 \mathrm{~mm}$

2. Oriented Strand Board (Durchschnitt DE), $240.00 \mathrm{~mm}$

3. Wood Fibre Insulating Boards, $240.00 \mathrm{~mm}$

4. Timber larch (12\% moisture / $10.7 \% \mathrm{H}_{2} \mathrm{O}$ content), $25.00 \mathrm{~mm}$

Fig. 4. Example of a graphic representation of construction layer created in eLCA tool.

By creating new modules in subgroups, a user can model constructions layer by layer and specify geometrical characteristics and materials for each layer. The tool automatically generates a graphic representation of the module including a specification of layers as displayed in the Fig. 4. The reference to the amount of building materials can be set either in square meters (e.g. walls) or in pieces (windows, doors).

Building materials can be chosen from four available data sets - generic (20), average (8), representative (8) and specific (3) varying in their kind and quality. The numbers in brackets refer to the number of data sets used while conducting the LCA on Swan. The generic data sets, used frequently in the LCA of Swan, do not represent the entire life cycle of chosen materials; still they can be used directly in the eLCA for the sake of completeness. Thus, generic datasets belong to Category $\mathrm{C}$ of the LCA data sets: although they are in accordance with DIN EN 15804, they have not been externally verified or reviewed.

One of the best features of the eLCA is an immediate availability to check results - even after adding a single building material or a module. The table includes the main impact categories and the potential of contribution to them by modules displayed in Fig. 3 or by single building materials (Ranking of Materials). The minimum useful life is automatically assigned to each material in accordance with "Nutzungsdauern von Bauteilen zur Lebenszyklusanalyse nach BNB" and for building components with VDI 2067 Blatt 1. 
TABLE 2. CATEGORIES FOR BUILDING CONSTRUCTION

IN ELCA (SOURCE OF INFORMATION: ELCA SOFTWARE PROGRAM)

\begin{tabular}{|c|c|c|}
\hline Building & Building services & Grounds \\
\hline 310 Excavation & 410 Water, waste water, gas plants & 510 Terrain surfaces \\
\hline 320 Foundation & 420 Heating supply systems & 520 Fixed surfaces \\
\hline 340 Exterior walls & 430 Ventilation systems & 530 Outdoor surfaces \\
\hline 350 Ceilings & 440 High-voltage power Installations & $\begin{array}{l}540 \text { Outdoor technical } \\
\text { installations }\end{array}$ \\
\hline 360 Roofs & $\begin{array}{l}450 \text { Telecommunications and information processing } \\
\text { systems }\end{array}$ & 550 Outdoor fixtures \\
\hline 370 Constructional components & 460 Conveyor systems & 560 Water areas \\
\hline \multirow[t]{3}{*}{$\begin{array}{l}390 \text { Other measures for } \\
\text { construction }\end{array}$} & 470 Use-specific systems & 570 Plant and crop area \\
\hline & 480 Building automation & 590 Other outdoor facilities \\
\hline & 490 Other measures for technical installations & \\
\hline
\end{tabular}

\subsection{Calculating the Energy Input}

Values for the energy input contribute to the parameter and scenario uncertainty and have to be considered with great care. For inputs, the software tool requires the Final Energy Demand (Endenergiebedarf) of a building, a figure found in the Energy Performance Certificate. In the case of Swan, $110 \mathrm{kWh} / \mathrm{m}^{2}$ a represent the final energy demand of pellets for heating and warm water. The ratio for hot water supply is approximately 60/40, i.e. heat generated by a pellet boiler covers $60 \%$ of the hot water demand and solar panels $40 \%$, which sounds very promising when taking into account the geographic location of Hamburg. Furthermore, a pellet boiler with a capacity of $9 \mathrm{~kW}$ has been searched in the databases, the generic dataset of a pellet boiler with a capacity fewer than $20 \mathrm{~kW}$ has been chosen, classified as: oekobau.dat: 8.6.01 Building service engineering / Use / Use heat generator from the database GaBi Version 6.5 - 2015. In the houseboat Swan, $20 \%$ of the heat produced in the boiler is transferred directly to the ambient environment (living room, Photo 2), however this could not have been modelled in the eLCA.

The next obligatory input is the net floor area (Nettogrundfläche NGF) according to the German Energy Saving Ordinance (EnEV), already mentioned in Chapter 2 Methods and Procedures. Although the design and the building of houseboats do not have to be in compliance with the Energy Saving Ordinance, these provisions have been respected in the case of a houseboat Swan.

In order to cover the electricity consumption, German-specific electricity mix (Strommix 2015) has been chosen, classified as oekobau.dat: 9.2.05 Others / Energy carrier - delivery free user / Electricity. This generic dataset was modelled in accordance with the EN 15804. There are more than 40 sources listed for the calculation of electricity mix 2015 for Germany; to demonstrate their variety in geography, time and object of a research, some are listed: 
- Wind in power 2011 - European statistics;

- Copper development association: overview of Recycled Copper;

- Austria's National Inventory Report 2010;

- Emission Estimation Technique Manual for Fossil Fuel Electric Power Generation Version 2.3;

- Emission estimations for $\mathrm{SO}_{2}, \mathrm{NO}_{2}, \mathrm{NMVOC}$ und $\mathrm{NH}_{3}$ in Germany 2000-2020.

\subsection{Boundary Conditions and Life Cycle Inventory List}

In agreement with our partners from the Architektenbüro PlanWerk, we assumed the houseboat service life of 50 years, with the cradle-to-grave system boundary and a functional unit defined as one square meter of a living area. Typically for houseboats, one extra building element - a pontoon - has been added to the eLCA. A pontoon, made of steel or concrete, is a solid floating structure, configured to float by displacing water and resist the magnitude of the lateral load.

Results may change dramatically when recycling materials after 50 years of use is included, option D in the eLCA. In that case, for example, a non-renewable material zinc for external walls would be favoured over wood due to the higher recyclability of the first mentioned. Table 3 depicts the list of the inventory analysis that was compiled for publication purposes due to the signed Confidential Agreement between the Architektenbüro PlanWerk and researchers at the HafenCity University in Hamburg.

To sum up Step 1, although the eLCA software program enables the researcher to conduct a very detailed LCA of any building, in the case of the LCA for Swan, only the most relevant materials and energy use (B6 category) have been taken into consideration. 
TABLE 3. COMPILED INVENTORY ANALYSIS LIST - HOUSEBOAT SWAN (COMPONENTS)

\begin{tabular}{|c|c|c|c|}
\hline Building Component & Material/Size & $\mathrm{m}^{2}$ & $\mathrm{~m}^{3}$ \\
\hline Pontoon & Reinforced concrete & & 56.148 \\
\hline Exterior wall and roof & $\begin{array}{l}\text { Wooden construction } / \mathrm{d}=26 \mathrm{~cm} \text { plus panelling } \\
\text { ( } 20 \% \text { wood / } 80 \% \text { insulation) }\end{array}$ & & 31.642 \\
\hline Dormer flanking & $\begin{array}{l}\text { Wooden construction } / \mathrm{d}=12 \mathrm{~cm} \text { plus panelling } \\
\text { ( } 20 \% \text { wood } / 80 \% \text { insulation) }\end{array}$ & & 3.552 \\
\hline Dormer roofs (flat roof) & $\begin{array}{l}\text { Wooden construction / } \mathrm{d}=22 \mathrm{~cm} \text { (in the middle) } \\
(20 \% \text { wood / } 80 \% \text { insulation) }\end{array}$ & & 10.01 \\
\hline $\begin{array}{l}\text { Floor } \\
\text { (wooden beams + insulation) }\end{array}$ & $\begin{array}{l}\text { Wooden construction / } \mathrm{d}=22 \mathrm{~cm} \text { (in the middle) } \\
(20 \% \text { wood / } 80 \% \text { insulation) }\end{array}$ & & 12.168 \\
\hline Additions for facade & & 50.54 & \\
\hline Windows & & 56.3 & \\
\hline Window frames & Wood (frame) $30 \%$ & 16.89 & \\
\hline Window triple glazing & Glass (Triple glazing) $70 \%$ & 39.41 & \\
\hline Front door & & 2.5 & \\
\hline Terraces & $\begin{array}{l}\text { Wooden beam substructure } 8 \mathrm{~cm} \cdot 10 \mathrm{~cm} \text { with } 70 \mathrm{~cm} \\
\text { spacing }\end{array}$ & & 0.4185 \\
\hline $\begin{array}{l}\text { Interior walls (double planked } \\
\text { on both sides with gypsum } \\
\text { plasterboard) }\end{array}$ & $\begin{array}{l}\text { Metal stands each with two layers of } 1.25 \mathrm{~mm} \text { gypsum } \\
\text { plasterboards }\end{array}$ & 54.08 & \\
\hline Inner doors & $0.885 \mathrm{~m} \cdot 2.135 \mathrm{~m}$ & 9.45 & \\
\hline \multicolumn{4}{|l|}{ Installations } \\
\hline Pellet Boiler & Fa. Wodtke, Net capacity: $9 \mathrm{~kW}$. Lifetime 15 years & & \\
\hline PV panels & $\begin{array}{l}\text { Area: } 12 \text { modules } \cdot 1.64 \mathrm{~m}^{2} \text {, net capacity } 3.06 \mathrm{~kW} \text {. } \\
\text { Lifetime } 20 \text { years }\end{array}$ & & \\
\hline Solar panels & Area: $6.7 \mathrm{~m}^{2}$, Paradigma. Lifetime 18 years & & \\
\hline Water tank & 500 1, Paradigma. Lifetime 20 years & & \\
\hline Air conditioning & Including Heat Recovery. Lifetime 12 years & & \\
\hline
\end{tabular}




\section{Parameter, Scenario And Model UnCertainty}

Terms related to the uncertainty, accuracy and precision are defined in [4] respectively as follows:

- The closeness of a measured or modelled value to its true value;

- The quality of being reproducible in amount or performance.

Most literature distinguishes three main categories on uncertainties:

- Parameter uncertainty related to input data from chosen databases with an uneven level of quality. Considering parameter uncertainty enhances our understanding of results' variability and it is the most frequently assessed type of uncertainty. In the case of the houseboat Swan, a new building component, a steel pontoon would have to be reevaluated. The material has not been modelled to be constantly exposed to moisture und thus it needs to be maintained more often in order to prevent corrosion. The results for assessing the impact of the steel pontoon will be higher than the outcome of the eLCA, although most emissions from steel are released during its production;

- Scenario uncertainty related to the various projected scenarios e.g. for the current and future electricity mix during the period of the lifetime of a houseboat. Further examples would include assumptions needed to be made for the chosen maintenance strategy of a houseboat (disregarded in the eLCA) or assumptions about the scenario of the development of the primary energy factor of wood pellets. These uncertainties are acknowledged - as they contribute to the uncertainty in the interpretation of the model results - but have not been considered;

- Model uncertainty refers to the set relations that are incorporated in the eLCA evaluation tool. For the sake of comprehensible explanation, these set relations must be simplified, e.g. it is assumed that the electricity delivered to the houseboat equals the German electricity mix for 2015. In this case, temporal characteristics of 50 years of a houseboat lifetime and spatial characteristics (Hamburg) is generalized in one single value.

As the title of the paper implies and many authors such as Pompon et al. [6] or Zhang et al. [7] confirm, deterministic values in both input values and results carry an illusion of great certainty achieved in the LCA process. Metaphorically speaking, the outcome of LCA software models deny the existence of the elephant in the room.

Various methods have been developed for assessing uncertainty in the LCA such as possibility theory applied to the uncertainty analysis of life cycle inventory [8], fuzzy theory, data quality indicators, expert judgement or stochastic modelling; conducting the uncertainty propagation by using the Monte Carlo simulation**. Pompon et al. [6] tested the lastmentioned method on the two entries from the Life Cycle Inventory from the manufacture of one functional unit of double skin façade, a flat glass cladding system to prove that the collection of extensive data is not necessary for undertaking an uncertainty parameter analysis (precisely expressed, for the characterization of the data distribution). Similarly, Zhang et al. [7] used a statistical method to calculate the probability distribution of the gathered data and Monte Carlo simulation to test randomly sampled inventory data on the LCA of a bridge.

All these methods relate to only one kind of uncertainty in the LCA, mostly to the parameter uncertainty and can be used only if the uncertainty is described by statistical functions. Parameters are then described as uncertainty distributions presenting the possible deviation of a parameter from its real value. If there is a space for an (un-computational) expert

\footnotetext{
** Note. Monte Carlo simulation consists of three steps: 1) generating samples of random values for all input variables; 2) applying the model to the generated values to calculate the model output 3) statistical analysis of the model output.
} 
judgement, then the evaluation/estimation of the uncertainty of model output is the right place. Bjorklund [9] presented the overview of 18 tools available to address 11 kinds of uncertainty. Most tools are able to address data inaccuracy and variability in objectives/sources; very few tools deal with mistakes and estimation of uncertainty.

To conclude this part ${ }^{\dagger \dagger}$, in the above-mentioned methods, the measure of uncertainty in the LCA is related to one term, such as probability and then an uncertainty analysis is built up upon the respective mathematical theory (such as the mathematical theory of probability). It goes without saying that all methods quantifying the uncertainty assessment do not decrease the uncertainty itself in the LCA. Some parts of the above-mentioned elephant in the room have been weighted but the elephant is still there.

Another option is to assess uncertainty by a qualitative assessment by choosing the "hot spot" of the uncertainty (expert opinion) in the LCA that has already been conducted. After examining the results from the above-mentioned first step for Swan; part of them displayed in the Section Results, the choice of energy use became evident. As Camila Camara (a Master student of the REAP at the HafenCity University) put it, "people are hot spots". Therefore, in this paper, input values for energy use in a houseboat Swan are qualitatively assessed. In contrast to the large amount of papers on the uncertainty, we do not verify the effectiveness of any of the above-mentioned methods but analyse present and future uncertainty while acknowledging it as an inherent part of any LCA.

The following section deals with the energy use and the relation of primary energy factors to the LCA.

\section{RESUltS AND DisCUSSION}

\subsection{On the Uncertainty in the Emission Factors of the Electricity Mix}

Whereas one of the terms related to the life cycle analysis is its accuracy or its assessment; emission factors for the electricity mix are studied and often artificially set to support future mix technologies. In other words, in Germany, primary energy factors have become tools to promote chosen technologies with the perspective of achieving the climate goals of Germany; reduction of end energy consumption for heating in buildings by $20 \%$ by 2020 (reference year 2008), increasing the share of renewable energy in the heating sector to $14 \%$ by 2020 , reduction of primary energy consumption by $20 \%$ by 2020 (reference year 2008) and the decrease of greenhouse gas emissions by $40 \%$ by 2020 (reference year 1990). Table 4 shows reported emission factors of electricity for production only in Germany $(2016,2017)$ and emission factors for electricity while considering the whole life cycle (including production plants) in the case of China, the Czech Republic and Poland.

For a building in a cold region in China, Zhang et al. [10] conducted simulations in MATLAB and assessed the basic case by both deterministic and stochastic approaches. The basic case with the simplified approach accounts for primary materials, such as iron, steel, cement products, wood products, gypsum powder, paint, insulation, and operational

\footnotetext{
${ }^{\dagger}$ Uncertainty analysis is also part of a new framework called: Life cycle Sustainability Assessment [11], in which:

a) Impact indicators include social and economic indicators,

b) Product-level assessment is broadened to the national and global level,

c) Accounting interrelations among the system elements (with uncertainty included) [11].

Regarding the system uncertainty, by increasing boundaries, as proposed in the Life Cycle Sustainable Assessment, further uncertainties emerge due to the need for new assumptions to be made while designing a mathematical model for defining dynamic relationships among system parameters. However, the Life Cycle Sustainability Assessment is out of the scope of this conference paper.
} 
energy use. Thus, it is comparable to the life cycle inventory list in Table 3 . To improve the reliability of results, Zhang et al. suggest modifications to be made to account for the potential underestimation of life cycle emissions by up to $10 \%$. The potential in increasing energy efficiency of power and heat generation shall not be neglected; Zhang et al. quantified this potential as a $60 \%$ decrease in life cycle emissions in China.

In Germany, such a dramatic increase of energy efficiency measures is not expected; although the factors for electricity mix, both in primary energy and carbon dioxide emissions equivalent emissions are gradually reduced due to a higher share of the renewable energy. Still, a primary energy factor for electricity in Germany, currently set at 1.8, is too optimistic. The newest overview of these factors is found in [1].

Burchart-Korol et al. [12] conducted the LCA on electricity in the Czech Republic and Poland by using ReCiPe method, SimaPro 8.2.3 software with the Ecoinvent 3.2 database. Energy policies of IEA Countries were used as the source of data for the Life Cycle Inventory, i.e. amount of sources in $\mathrm{GWh}_{\mathrm{e}}$ for gross electricity generation from 2000 to 2050 . When the total gross electricity generation from IEA Energy Policies is compared with data from EUROSTAT for 2005, 2010 and 2015, negligible deviations at around $1 \%$ up to $5 \%$ are observed.

An extra low average emission factor of electricity at $0.003 \mathrm{~kg} \mathrm{CO} 2 \mathrm{e} / \mathrm{kWh}$ is based on reported emissions from specific electricity suppliers in Sweden. Guldbrandssson et al. estimated a higher uncertainty $(+/-20 \%)$ for Swedish electricity due to the higher share of renewable energy, especially biofuels [13].

TABle 4. AVERAge EMISSION FACTORS FOR EleCtricity MiX - 2 METHOdOLOGIES

\begin{tabular}{lll}
\hline & $\begin{array}{l}\text { Emissions in the production and } \\
\text { construction, \% of the life cycle impact }\end{array}$ & $\begin{array}{l}\text { Average emission factor for } \\
\text { electricity, } \mathrm{gCO}_{2} \mathrm{e} / \mathrm{kWh}\end{array}$ \\
\hline Houseboat Swan & 10.3 & 534.5 \\
Residential Building, Harbin, China [10] & 13.4 & 1130 \\
Germany, 2016 & - & 471 \\
Germany, 2017 & - & 435 \\
Hamburg, Vattenfall, Klassik, 2017 & - & 295 \\
Sweden [13] & - & 3 \\
Czech Republic [9] year 2000 & - & 985 \\
Poland [12] year 2000 & - & 1136 \\
\hline
\end{tabular}

To sum up, in contrast to the more widespread notion of "specific carbon dioxide emissions" where energy input for electricity generation is seen to "appear out of the blue", the LCA for electricity includes generation technologies as listed for example in [12] and studied in [14]. In other words, while considering the whole production chain, no production technology is carbon free; for example, Sovacool [15] screened 103 life cycle studies of greenhouse gas-equivalent emissions for nuclear power plants with the mean value of $66 \mathrm{gCO}_{2} \mathrm{e} / \mathrm{kWh}$. 


\subsection{Implications for the Houseboat Swan}

As energy-saving measures have progressed, many authors e.g. Zhang et al. [10] started to emphasize the embodied emissions from production and construction activities. Our results cannot confirm this shift in focus; the operation stage (B6 - energy use) has been highlighted as the main contributor to the Global Warming Potential and impact indicators related to the primary energy.

Table 5 shows the amount of primary energy directly used as a material for components in the houseboat (oil products in sealings, wood terrace) compared to the primary energy used as Energy. The second mentioned includes energy required to produce building components of a houseboat (in literature known as embodied energy) and energy use in the category B6.

TABLE 5. PRIMARY ENERGY IN MATERIALS

(Stoffliche Nutzung) VS. Primary Energy in EnERgy. Houseboat SWAN

\begin{tabular}{llll}
\hline & Indicator & Unit & Total $/ \mathrm{m}^{2} \mathrm{NGFa}$ \\
\hline Houseboat Swan & Primary energy in Materials & MJ & 29.10 \\
& Primary energy in Energy & MJ & 620.51 \\
\hline
\end{tabular}

Both the eLCA and primary energy calculation take into account renewable energy sources that are generated and used on-site. In the eLCA tool - the amount of electricity produced by monocrystalline PV modules was deducted from the final amount of energy needed as there is no dataset available for the electricity generated by PV panels. Just for illustration purposes, some results from the eLCA tool are presented in Table 6 and Table 7, although displaying them as point estimates is an extreme overestimation of their exactness.

Moreover, the eLCA program does not seem to be the right tool for making the decision on the heating installation; e.g. the scenario of connecting the houseboat to the district heating network in Hamburg massively increased the emissions, as the tool calculates with the generic dataset based on national average mix of fuels (35\% lignite, $65 \%$ natural gas) used for the district heating network with $9.5 \%$ of average heat losses. As a theoretical exercise, even if emissions from the Certificate $\$$ for district heating network in Hamburg were incorporated in the model $\left(131 \mathrm{gCO}_{2} / \mathrm{kWh}\right.$ at the leaving point from the power plant and $146 \mathrm{gCO}_{2} / \mathrm{kWh}$ at the customer substation), they would not be able to compete with the wood pellets $\left(42 \mathrm{gCO}_{2} / \mathrm{kWh}\right)$.

The data set for electricity requires special attention. In the calculation of the electricity mix, data from other sources such as other background databases, literature data, etc. have been used as it is stated in the information sheet for a dataset. Still, no electricity forecast has been incorporated into the software program. Therefore, the electricity for the last year of the houseboat in use (e.g. 2066) is calculated with the same electricity mix as in 2015.

\$4 The Certificate is based on the operation data 2011-2013, issued by the Technical University in Dresden in accordance with the AFGW Rules FW 309- Part 6 and valid until 29 November 2024. 
TABLE 6. RESULTS OF THE LIFE CYCLE ASSESSMENT FOR Houseboat Swan Provided By ELCA SOFTwARE FOR PHASES A1-C4

\begin{tabular}{|c|c|c|c|c|c|c|c|}
\hline $\begin{array}{l}\text { Impact } \\
\text { Category }\end{array}$ & Units & Total $/ \mathrm{m}^{2}{ }_{\text {NGF }}$ & $\mathrm{A} 1-\mathrm{A} 3$ & B6 & $\mathrm{C} 3$ & $\mathrm{C} 4$ & Maintenance \\
\hline GWP & $\mathrm{kg} \mathrm{CO}_{2}$ equiv. & 31.83 & 7.6 & 16.51 & 3.97 & 0.46 & 3.29 \\
\hline PEtot & MJ & 649.61 & 224.57 & 381.88 & -20.27 & 0.90 & 62.53 \\
\hline PENRT & MJ & 399.36 & 135.51 & 216.30 & 0.72 & 0.82 & 46.01 \\
\hline PERT & MJ & 250.28 & 89.1 & 165.58 & -21 & 0.08 & 16.52 \\
\hline
\end{tabular}

TABLE 7. RESUlTS OF THE LIFE CYCLE ASSESSMENT FOR

Houseboat Swan Provided by ELCA SofTware FOR PHASES D AND SERVICING

\begin{tabular}{|c|c|c|c|c|c|c|}
\hline $\begin{array}{l}\text { Impact } \\
\text { Category }\end{array}$ & Units & $\begin{array}{l}\text { Functional } \\
\text { unit } / \mathrm{m}^{2}{ }_{\mathrm{NGF}} \mathrm{a}\end{array}$ & $\begin{array}{l}\text { D Total (Energy } \\
\text { and Material) }\end{array}$ & $\begin{array}{l}\text { D Energy } \\
\text { (DIN EN } \\
15978)\end{array}$ & $\begin{array}{l}\text { D Material } \\
\text { (DIN EN } \\
15804)\end{array}$ & Servicing \\
\hline GWP & $\begin{array}{l}\mathrm{kg} \mathrm{CO}_{2} \\
\text { equiv. }\end{array}$ & & -12.34 & -7.39 & -4.95 & 3.29 \\
\hline
\end{tabular}

\subsection{List of Uncertainties with the Estimation on the Global Warming Potential for the Future 50 Years of the Swan Life}

\section{TABLE 8. UNCERTAINTIES FOR GWP (ENERGY USE) ( $\mathrm{GCO}_{2}$-EQUIV.)}

\begin{tabular}{|c|c|c|}
\hline $\begin{array}{l}\text { Description of uncertainty, } \\
\text { quality of database }\end{array}$ & $\begin{array}{l}\text { Present values in the eLCA (a) } \\
\text { Present value (b) }\end{array}$ & Estimation of the total results for 50 years \\
\hline $\begin{array}{l}\text { Electricity, eLCA, average } \\
\text { dataset }(3.6 \mathrm{MJ})\end{array}$ & $534.5(\mathrm{a})$ & $\begin{array}{l}\text { Extreme cause of uncertainty } \\
\text { Real emissions: } 30-40 \% \text { lower }\end{array}$ \\
\hline $\begin{array}{l}\text { Deviation of electricity } \\
\text { emissions in Hamburg from } \\
\text { the national average mix }\end{array}$ & $239.9(b)$ & $\begin{array}{l}\text { Inherent uncertainty in every LCA } \\
\text { Real emissions: 5-10 \% lower }\end{array}$ \\
\hline $\begin{array}{l}\text { Wood pellets, } \mathrm{D},(\mathrm{GaBi} \\
\text { version } 6.5-2015 \text {, generic } \\
\text { dataset), thermal energy } \\
(3.6 \mathrm{MJ})\end{array}$ & $42.13(\mathrm{a})$ & $\begin{array}{l}\text { Forecasts are not available } \\
\text { Any direction possible. The fuel can be out of German } \\
\text { market by } 2065\end{array}$ \\
\hline $\begin{array}{l}\text { PV panels (electricity } \\
\text { distracted from the total } \\
\text { electricity consumption) }\end{array}$ & 25 (b, Gemis 5.0 beta) & $\begin{array}{l}\text { Emission during the electricity production }- \text { negligible } \\
\text { Real emissions after } 2035 \text { will be lower due to the } \\
\text { technology development }\end{array}$ \\
\hline
\end{tabular}

Forecasts for future development of wood pellet emissions have not been found; other sources estimate current emissions at $17 \mathrm{gCO}_{2}$ equiv., [Gemis 5.0 beta] and $40 \mathrm{gCO}_{2}$ equiv. [1]. 


\section{Conclusions}

Partial conclusions are summarized as follows:

- Changes in the behaviour of residents through 50 years and in the energy mix of Germany (the country going through a rapid energy transition) must influence the LCA results to a greater degree than the material and construction process phases. In this respect, the impact of the construction process of the houseboat on the categories is negligible and correctly not considered in the eLCA;

- Final results, expressed by a numeric indicator of the potential in relation to the impact category, create an illusion of certainty and are misleading. Intervals would better mirror uncertainty in the LCA; on the other hand, one can question their usefulness for a decision making process;

- Calculation of primary energy factor for energy inputs face similar types of uncertainty which is not communicated to the public as factors are mostly set to support current energy and climate policies in Germany;

- Interpretation of results (consuming more renewable energy vs. less non-renewable energy ${ }^{\S \S}$ ) are influenced by the goal-setting in the energy policies of a respective country and current share of renewable energy in the electricity or natural gas mix;

- There is no one-fit-all solution for accuracy in the LCAs. In our concrete case, cooperation of experts on houseboats, LCA practitioners and energy engineers made deeper understanding uncertainty in the LCA of houseboats possible without the risk of the increased complexity that would just add to the confusion;

- The concept of the security of energy supply is well examined for fossil fuels (in the LCA terms: non-renewable primary energy total). In the future, the LCA may assist in understanding the concept of security of material supply, especially regarding rare materials used for new technologies utilizing renewable energy.

In general, since the internalization of life cycle thinking has not been fully adopted outside of a few disciplines such as environmental sciences or architecture, the practical use of the LCA is still limited. According to expert opinion in Germany, until the LCA becomes an inherent part of the evaluation of new buildings, similar to energy building certificates, the LCA will not make a change in the perception and decision-making process of stakeholders.

Coming back to the (non-)imaginary elephant from the title of the paper, it is confirmed the elephant has not left the room nor would the assessment of some of its body parts improve our knowledge of its size. Still, it can be located.

\section{ACKNOWLEDGEMENT}

We would like to thank Daniel Wickersheim (PlanWerk Architektur \& Energieberatung Wickersheim Mannsfeld PartG $\mathrm{mbB} \&$ Coop Water House $\mathrm{GmbH}$,) for the exemplary cooperation between our teams and for providing all necessary information for the houseboat Swan. Furthermore, special thanks to Joost Hartwig (ina Planungsgesellschaft mbH) for consulting the eLCA software tool as well as general issues concerning the life cycle assessment and the role of renewable energy in the future energy systems of Germany. We are particularly grateful for photos of the houseboat Swan provided by Cesar Pascoli.

\footnotetext{
$\S \S$ "Any direction possible" is the result of the analysis of two processes that are expected to follow opposite directions: while electricity needed for the wood pellets may/will have less impact potential on the GWP, the scarcity of resources and growth population does not allow us to make a statement on the availability of this fuel in 2065 (while taking into account the technology progress).
} 


\section{Author Contributions}

Maria Grajcar studied and wrote for the eLCA software program, energy use and the aspect of uncertainty in overall results. Kristina Rumiantceva conducted an analysis of PV panels and took part in the LCA, of one of the three houseboats during the winter semester. Prof. Ingo Weidlich contributed by reviewing, supervising and criticising the elephant in the room.

\section{REFERENCES}

[1] 7-03-17 Untersuchung zu Primärenergiefaktoren. (7-03-17 Study of primary energy factors). Final report. Berlin: Heilderberg, 2018. (in German)

[2] Grajcar M. Houseboat Swan. Based on the data from: Bundesinstitut für Bau-, Stadt- und Raumforschung. eLCA v0.9.5 BETA (software program). Available: https://www.bauteileditor.de

[3] Ökobaudat - Handbuch. Technische Beschreibung von Datensätzen in Ökobaudat inkl. Anleitung für Anlieferung und Nutzung von Datensätzen. Version 1.0. (Ökobaudat - Manual. Technical description of data sets in Ökobaudat including instructions for delivery and use of data records. Version 1.0.) Berlin: Federal Institute for Research on Building, Urban Affairs and Spatial Development, 2018. Available: https://www.oekobaudat.de/fileadmin/downloads/2018-03-18_OEBD-Handbuch_pub_01.pdf (in German)

[4] Rosenbaum R. K., Georgiadis S., Fantke P. Uncertainty Management and Sensitivity Analysis. Chapter 11. Life Cycle Assessment: Theory and Practise. Springer, 2017. doi:10.1007/978-3-319-56475-3 11

[5] Pikon K. Abiotic depletion in energy and waste management systems. Polityka Energetyczna 2012.

[6] Pomponi F., D'Amico B., Moncaster A. M. A Method to Facilitate Uncertainty Analysis in LCAs of Buildings. Energies 2017:10(4):524. doi:10.3390/en10040524

[7] Zhang Y.-R., Wu W.-J., Wang Y.-F. Bridge life cycle assessment with data uncertainty. The International Journal of Life Cycle Assessment 2016:21:569-576. doi:10.1007/s11367-016-1035-7

[8] André J., Lopes D. On the use of possibility theory in uncertainty analysis of life cycle inventory. The International Journal of Life Cycle Assessment 2012:17(3):350-361. doi:10.1007/s11367-011-0364-9

[9] Björklund A. E. Survey of approaches to improve reliability in LCA. The International Journal of Life Cycle Assessment 2002:7:64. doi:10.1007/BF02978849

[10] Zhang X., Zheng R., Wang F. Uncertainty in the life cycle assessment of building emissions: A comparative case study of stochastic approaches. Building and Environment 2019:147:121-131. doi:10.1016/j.buildenv.2018.10.016

[11] Onat N. C., Kucukvar M., Halog A., Cloutier S. Systems thinking for life cycle sustainability assessment: A review of recent developments, applications, and future perspectives. Sustainability 2017:9(5):706. doi:10.3390/su9050706

[12] Burchart-Korol D., Pustejovska P., Blaut A., Jursova S., Korol J. Comparative life cycle assessment of current and future electricity generation systems in the Czech Republic and Poland. The International Journal of Life Cycle Assessment 2018:23:2165-2177. doi:10.1007/s11367-018-1450-Z

[13] Guldbrandsson F., Malmodin J., Bondesson A. Quantifying the life cycle assessment uncertainty in the information and communication technology sector. Life Cycle Management (LCM), 2011. Available: http://www.lcm2019.org/

[14] Soimakallio S., Kiviluoma J., Saikku L. The complexity and challenges of determining GHG (greenhouse gas) emissions from grid electricity consumption and conservation in LCA (life cycle assessment): A methodological review. Energy 2011:36(12):6705-6713. doi:10.1016/j.energy.2011.10.028

[15] Sovacool B. Valuing the Greenhouse Gas Emissions from Nuclear Power: A Critical Survey. Energy Policy 2008:36:2940-2953. doi:10.1016/j.enpol.2008.04.017 